\title{
ANALYSIS OF SOLID WASTE MANAGEMENT IN MAITAMA, ABUJA, NIGERIA
}

\author{
JOSEPH FREEDOM GAJERE ${ }^{1}$, FOLORUNSHO JOSEPH OLANIYI ${ }^{2}$, \\ YUSUF YAKUBU OBADAKI ${ }^{1} \&$ ARUYA EMMANUEL IRUOBE ${ }^{1}$ \\ ${ }^{1}$ Department of Geography and Environmental Management, Ahmadu Bello University, Nigeria \\ ${ }^{2}$ Department of Geography, Federal University, Lokoja, Nigeria
}

\begin{abstract}
Municipal solid waste management constitutes one of the most crucial health and environmental problems facing the world especially African cities. Most cities spend $20-50 \%$ of their annual budget on solid waste management. This study analysed solid waste management in Maitama, Abuja. The set objectives were to identify the structure of solid waste management in Maitama district, the sustainability of the process from generation to disposal and the role of scavengers in solid waste management in Maitama. These were carried out by administration of questionnaires to the residents and waste managers. The socio-demographic characteristics in the study revealed that there were more women than men in the study area. The study also revealed the heterogeneous nature of solid waste composition in the area which may require sorting for effective recycling process. Although most residents adjudged the services (collection and disposal) of the solid waste managers as satisfactory, others recounted poor sanitary habits of respondents and refusal to pay waste managers as the problems of solid waste management in the study area. The waste managers regarded this as unfortunate because the meagre charges do not fully cover the cost of waste collection, transportation and disposal. Therefore the study recommended that in order to ensure efficient solid waste management in the study area, there should be increased awareness to encourage residents to be consistent in payment and waste separation should be done at source to make waste disposal easier.

Keywords: Abuja, Maitama, municipal, solid waste management.
\end{abstract}

\section{INTRODUCTION}

Waste is an unavoidable by-product of human activity [1]. Economic development and rising living standards in some regions in the world have led to increases in the quantity and complexity of generated waste, whilst industrial diversification and the provision of expanded health-care facilities have added substantial quantities of industrial hazardous waste and biomedical waste into the waste stream with potentially severe environmental and human health consequences [2]-[4].

Solid waste management is the discipline associated with the control of generation, storage, collection, transfer and transport, processing and disposal of solid waste in a manner that is in accordance with the best principles of public health, economic, engineering, conservation, aesthetics and other environment consideration that is also responsive to public attitudes [5]. Municipal solid waste management is an important part of urban infrastructure that ensures the protection of the environment and human health [6].

The current capacity of most solid waste management system in Africa is inadequate and too slow to meet the increasing demand of solid waste generated [7]-[9].

\subsection{The research problem}

According to Ogu [10], a major consequence of rapid urbanization is the growing generation of waste which many city authorities face unprecedented challenges in managing. Kgosiesele and Zhaohui [11] stated that among the various kinds of waste, municipal solid waste is the most generated type of waste. Municipal solid waste (MSW) 
comprises of domestic, commercial and industrial waste generated in a given municipality or locality [12]. Fakere et al. [13] opined that domestic waste constitutes the highest percentage of waste generated in Akure when compared with other sources which is similar to the situation in several other South-Western Nigerian cities.

In most developing countries, the problems associated with solid waste management are more acute than in the developed countries [14]. Lack of financial resources and infrastructure to deal with solid waste creates a vicious cycle; lack of resources leads to low quality of service provision which leads to fewer people willing to pay for services, which in turn further erodes the resource base and so on [14]-[17]. Troschinetz [18] further observed that in many developing countries, adequate funds are not available to implement technology that is reliable and appropriate.

However despite the structure put in place by the administration of the Federal Capital Territory (FCT) to collect and manage solid waste one still finds wastes littered along the major streets in Maitama District in some instances. It is against this background that this study intends to fill the knowledge gap. The aim of this study is to analyse the structure and sustainability of solid waste management in Maitama District of Abuja. The objectives of this study are; identifying the residents of the study area, examining the coordination of the solid waste in the district, examining the sustainability of the process of solid waste management from generation to disposal and identifying the role of scavengers in solid waste management in Maitama.

\subsection{The study area}

The Federal Capital Territory is located just north of the confluence of Niger and Benue rivers. The FCT is located between latitudes $8^{\circ} 25^{\prime}-9^{\circ} 20^{\prime}$ north of the Equator and longitudes $6^{\circ} 45^{\prime}-7^{\circ} 39^{\prime}$ east of the Greenwich Meridian (Fig. 1). It has a landmass of approximately $8000 \mathrm{~km}^{2}$, of which the actual city occupies $250 \mathrm{~km}^{2}$ [19]. The major problems of the FCT include transportation, accommodation and unemployment. According to Gaza [20], the influx of migrant into the FCT is for perceived better economic opportunities.

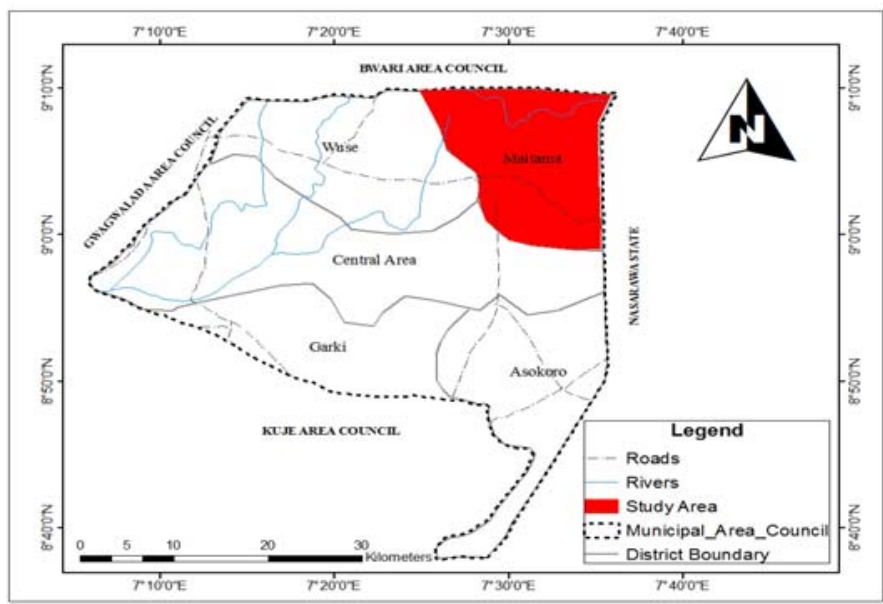

Figure 1: Abuja Municipal Council showing study area. (Source: Modified from the Administrative Map of FCT.) 


\section{METHODOLOGY}

In order to achieve the aim and objectives of this study the study required data from basically primary source which was derived from structured questionnaire that was developed and administered to respondents in Maitama District of FCT Abuja. Systematic sampling was used to administer the questionnaire to the residents of Maitama District by picking every other household along the major streets. A total of 100,000 households in the district served as the study population, Krejcie and Morgan was used to determine the sample size of 380 . Of these 373 were returned.

Descriptive statistical test was used in analyzing the data for this study using tables, percentages and figures. All statistical analyses were carried out using Microsoft Excel.

\section{RESULTS AND DISCUSSION}

\subsection{Socio-demographic characteristics of respondents}

Majority of the respondents were observed to be female (Table 1). Age is an important socio-demographic attribute because it reveals the participation of respondents across age groups. As indicated by Table 1, respondents within the age of 41-50 years constitute the highest proportion with $36.5 \%$, followed by those aged between $31-40$ years that constituted $32.4 \%$. The deduction from this is that there is a positive correlation between age group and participation in domestic waste management.

The result from Table 1 also reveals that $81.8 \%$ of the respondents are married while $17.2 \%$ and $1.1 \%$ are single and separated respectively. The belief in African culture that married women are responsible for the sanitation of the home and its immediate environment could be the reason for the result.

Table 1: Socio-demographic characteristics of respondents in the study area.

\begin{tabular}{|l|c|c|}
\hline Sex & Frequency & Percentage (\%) \\
\hline Male & 130 & 34.9 \\
Female & 243 & 65.1 \\
Total & $\mathbf{3 7 3}$ & $\mathbf{1 0 0}$ \\
\hline Age & Frequency & Percentage (\%) \\
\hline Less than 20 years & 4 & 1.1 \\
21-30 years & 80 & 21.4 \\
31-40 years & 121 & 32.4 \\
41-50 years & 136 & 36.5 \\
51-60 years & 32 & 8.6 \\
Total & $\mathbf{3 7 3}$ & $\mathbf{1 0 0}$ \\
\hline Marital status & Frequency & Percentage (\%) \\
\hline Married & 305 & 81.8 \\
Single & 64 & 17.2 \\
Separated & 4 & 1.1 \\
Total & $\mathbf{3 7 3}$ & $\mathbf{1 0 0}$ \\
\hline Household size & Frequency & Percentage (\%) \\
\hline 1-3 & 112 & 30 \\
4-6 & 191 & 51.2 \\
7-10 & 70 & 18.8 \\
Total & $\mathbf{3 7 3}$ & $\mathbf{1 0 0}$ \\
\hline
\end{tabular}


In most cases, the family size of respondents determine the quantity of domestic solid waste generated because the higher the household size, the higher the volume of waste generated. From Table 1,30\% of the respondents reside in homes with a population between 1 and 3 while $51.2 \%$ and $18.8 \%$ of the respondents have a household size $4-6$ people and 7-10 people respectively. The implication here is that majority of houses in the area have an average of 4-10 persons. Given the correlation between household size and waste [21] one should expect much generation of waste in the study area.

\subsection{Socio-economic characteristics of respondents}

The socio-economic characteristics of respondents includes indices such as occupation, educational status and income level of respondents. Occupation determines income level of a person thus the relationship between occupation and method of solid waste disposal cannot be over emphasized. Table 2 shows that $52.5 \%$ of the respondents are civil servants. This is followed by respondents on self-employment with $30 \%$. It is expected that the respondents should have positive attitudes towards participating in domestic waste management.

Educational status reflects the participation of people in domestic solid waste management. Table 2 reveals that majority of the respondents have attended tertiary institution representing $92 \%$ while $8 \%$ agreed to have attended up to secondary school which indicates that the respondents should easily and readily cooperate in achieving a healthy environment through effective and efficient domestic waste management methods. This finding is in line with Shafiul and Mansoor [22] report of positive relationship between educational attainment, occupation, income as well as types and quantity of household waste generated.

Income is a major determinant of standard of living given that it informs the method people use to manage their household waste. As revealed in Table 2, majority of the respondents $(92.8 \%)$ earn above $\$ 20,000$ monthly. This is followed by those between

Table 2: Socio-economic characteristics of respondents in the study area.

\begin{tabular}{|l|c|c|}
\hline Occupation & Frequency & Percentage (\%) \\
\hline Civil servant & 196 & 52.5 \\
Trader & 12 & 3.2 \\
Self employed & 112 & 30 \\
Unemployed & 19 & 5.1 \\
Others & 34 & 9.1 \\
Total & $\mathbf{3 7 3}$ & $\mathbf{1 0 0}$ \\
\hline Educational status & Frequency & Percentage (\%) \\
\hline Secondary school & 30 & 8 \\
Tertiary & 343 & 92 \\
Total & $\mathbf{3 7 3}$ & $\mathbf{1 0 0}$ \\
\hline Monthly income (\$) & Frequency & Percentage (\%) \\
\hline 5,001-10,000 & 4 & 1.1 \\
10,001-15,000 & 8 & 2.1 \\
20,000 above & 346 & 92.8 \\
No entry & 15 & 4 \\
Total & $\mathbf{3 7 3}$ & $\mathbf{1 0 0}$ \\
\hline
\end{tabular}


N10,000- 15,000 representing 2.1\%. The level of income of the respondents might be connected with high educational status of the respondents which in most cases determine their income.

\subsection{Composition of MSW and disposal methods in the study area}

The composition of municipal solid waste in Maitama is presented in Table 3.

From Table 3, $2.1 \%$ of the respondents generate only garbage type of waste, $1.1 \%$ each for both plastic and bottle only while $95.7 \%$ generated all types of domestic solid wastes. This reveals the heterogeneous composition of solid waste in the area which may require sorting for effective recycling process.

On the other hand, the methods of disposal of these waste are shown in Table 4. Table 4 shows that collection of waste by the waste managers is highest with $78 \%$ while $13.9 \%$, $4.3 \%$, and $3.2 \%$ of the respondents dispose their waste through burning, taken to designated points along the street and burrowed pit/backyard respectively.

This reveals an organized system of municipal solid waste management system in the area as against open dumping, land filling, incineration and composting methods of solid waste disposal and management as identified in the study of Babayemi and Dauda [17].

\subsection{The structure of municipal solid waste in the study area}

\subsubsection{Solid waste collection method}

Municipal solid waste collection includes both formal (government authorities, private waste managers) and informal (scavengers, waste pickers) in the study area as shown in Table 5. Table 5 confirms that $50.1 \%$ of the respondents reported that government waste managers collect their solid domestic waste, private waste managers with $45.6 \%$, scavengers with $1.1 \%$ and others with $3.2 \%$.

Table 3: Waste type generated.

\begin{tabular}{|l|c|c|}
\hline Waste type & Frequency & Percentage \\
\hline Garbage only & 8 & 2.1 \\
\hline Plastic only & 4 & 1.1 \\
\hline Bottle only & 4 & 1.1 \\
All of the above & 357 & 95.7 \\
\hline Total & $\mathbf{3 7 3}$ & $\mathbf{1 0 0}$ \\
\hline
\end{tabular}

Table 4: Methods of waste disposal.

\begin{tabular}{|l|c|c|}
\hline Disposal method & Frequency & Percentage \\
\hline Burrowed pit/backyard & 12 & 3.2 \\
\hline Burn them & 52 & 13.9 \\
\hline Collected by waste manager & 293 & 78.6 \\
\hline Taken to designated points & 16 & 4.3 \\
\hline Total & $\mathbf{3 7 3}$ & $\mathbf{1 0 0}$ \\
\hline
\end{tabular}


Table 5: Waste collection medium.

\begin{tabular}{|l|c|c|}
\hline Collection medium & Frequency & Percentage \\
\hline Government authority & 187 & 50.1 \\
\hline Private waste managers & 170 & 45.6 \\
\hline Scavengers & 4 & 1.1 \\
\hline Others & 12 & 3.2 \\
\hline Total & $\mathbf{3 7 3}$ & $\mathbf{1 0 0}$ \\
\hline
\end{tabular}

Table 6: Frequency of waste collection.

\begin{tabular}{|l|c|c|}
\hline Frequency of collection & Frequency & Percentage \\
\hline Weekly & 12 & 3.2 \\
\hline Monthly & 4 & 1.1 \\
\hline Others & 325 & 87.1 \\
\hline No entry & 32 & 8.6 \\
\hline Total & $\mathbf{3 7 3}$ & $\mathbf{1 0 0}$ \\
\hline
\end{tabular}

Table 7: Distance to respondents home.

\begin{tabular}{|l|c|c|}
\hline Distance & Frequency & Percentage \\
\hline Less than $500 \mathrm{~m}$ & 357 & 95.7 \\
\hline $500 \mathrm{~m}-1 \mathrm{~km}$ & 4 & 1.1 \\
\hline Above $1 \mathrm{~km}$ & 8 & 2.1 \\
\hline No entry & 4 & 1.1 \\
\hline Total & $\mathbf{3 7 3}$ & $\mathbf{1 0 0}$ \\
\hline
\end{tabular}

The above shows the role of public sector in solid waste management in the study area as against the findings of Sunday [23] where individuals accounted for $65 \%$ of collection of waste in Ughelli. Also, the frequency of Municipal solid waste collection in the study area is shown in Table 6.

As shown in Table 6 most of the respondents $(87.1 \%)$ reported different times of solid waste collection ranging daily, twice or thrice in a week, while $3.2 \%$ and $1.1 \%$ reported that their waste are collected once a week and once a month respectively.

On the other hand, Table 7 shows the range of distances between households and waste collection sites because as revealed by Agunwamba [19], the longer the distance of collection sites from residents, the higher the possibility of indiscriminate dumping.

Table 7 above revealed that most respondents walk a distance of less than $500 \mathrm{~m}$ to dispose their domestic solid waste which represents $95.7 \%$. This implies that the residents dispose their solid waste within their immediate environment. It was also revealed that majority of the respondents have standard waste bin in the study area. This indicates efficiency in management of municipal solid waste. 
3.5 The sustainability of the process of solid waste from generation to disposal

\subsubsection{Cost of waste disposal}

The response with respect to how much is paid for waste disposal service is presented in Table 8 . The range of cost captures the cost of disposal by both private and government bodies, dependent on their availability.

Table 8 shows that majority of the respondents pay between $\$ 25,000-\$ 30,000$ per annum (about $\$ 500$ weekly) for the collection of their solid waste with $45.3 \%$. This can be said to be low when compared to the amount paid by residents or commercial outfit owners in the developed countries.

\subsubsection{Perception of respondents on solid waste collection fee}

The perception of residents on waste collection fee is shown in Table 9. It shows that over half of the respondents $(74.8 \%)$ agreed that the charges are moderate as observed earlier while $5.1 \%$ and $2.1 \%$ represent the expensive and very expensive perception on payment rate respectively.

Since $92.8 \%$ of the respondents earn at least $\$ 20,000$ per month which will amount to N240,000 per annum (Table 2) and majority of the respondents $(69.7 \%)$ indicated that the cost of service for waste collection was $\$ 30000$ or less (Table 8 ). It can be clearly seen that majority of the households pay about $12.5 \%$ or less of their income annually for waste disposal. This shows that the charges collected by the waste managers do not constitute a financial burden to majority of the residents as a result one should expect prompt payment of charges.

\subsubsection{Assessment of solid waste management service}

The study revealed that $92.8 \%$ of the respondents adjudge the services of the solid waste managers as satisfactory while $2.1 \%$ and $5.1 \%$ agreed that the services are poor and very good respectively. This might be connected with the use of private waste managers whose

Table 8: Cost for the service.

\begin{tabular}{|l|c|c|}
\hline Cost per annum (\$) & Frequency & Percentage \\
\hline $10,001-15,000$ & 91 & 24.4 \\
\hline $25,001-30,000$ & 169 & 45.3 \\
\hline Above 35,000 & 73 & 19.6 \\
\hline No Response & 40 & 10.7 \\
\hline Total & $\mathbf{3 7 3}$ & $\mathbf{1 0 0}$ \\
\hline
\end{tabular}

Table 9: Payment rate.

\begin{tabular}{|l|c|c|}
\hline Payment rate & Frequency & Percentage \\
\hline Cheap & 27 & 7.2 \\
\hline Moderate & 279 & 74.8 \\
\hline Expensive & 19 & 5.1 \\
\hline Very expensive & 8 & 2.1 \\
\hline No entry & 40 & 10.7 \\
\hline Total & $\mathbf{3 7 3}$ & $\mathbf{1 0 0}$ \\
\hline
\end{tabular}


promptness in collection and disposal of waste cannot be compared with public managers. This result agrees with Wali [24] that $64.3 \%$ severity index of the public was satisfied with the current solid waste management system.

\subsection{Problems of solid waste management in the study area}

Table 10 on the other hand shows that non-payment of waste levies $(67 \%)$ is the major problem of solid waste management. This corroborates UNEP [25], that despite the assigned fees for waste collection and transportation, most people are unable to pay resulting in the revenue collected contributing to less than the money needed to run the service. Consequently, this might have reflected on the level of services offered.

About $11.3 \%$ of the respondents consider poor sanitary habits of residents as a serious problem in the study area. This can be the reason for the litters observed in the study area in some instances.

\subsection{The role of scavengers in solid waste management in the study area}

The recyclable materials from solid waste are often collected at the source by scavengers and reusable waste collectors patrolling the residential areas. Residents often times sell their recyclables to buyers who call door-to-door or sometimes deliver recyclables to the service sites themselves. The buyers in turn sell the materials to a nearby recyclables distribution centre where the materials are sorted and sold to factories as raw or processed materials. Fig. 2 shows that $94 \%$ of the respondents do not patronize services of scavengers while $6 \%$ agreed to do so which indicates that the activities of informal solid waste sector consisting of itinerant waste collectors and scavengers are restricted.

Table 10: Problems of solid waste management.

\begin{tabular}{|l|c|c|}
\hline Problems & Frequency & Percentage \\
\hline Lack of waste facilities & 23 & 6.2 \\
\hline Poor sanitary habits of the residents & 42 & 11.3 \\
\hline Large population & 38 & 10.2 \\
\hline Non-payment of waste levies & 250 & 67 \\
\hline Improper physical planning & 16 & 4.3 \\
\hline High waste charges & 4 & 1.1 \\
\hline Total & $\mathbf{3 7 3}$ & $\mathbf{1 0 0}$ \\
\hline
\end{tabular}

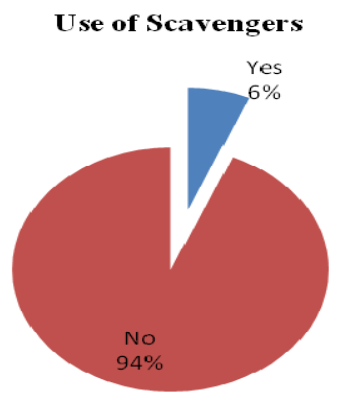

Figure 2: Use of scavengers. 
Indeed, majority of the respondents are of the view that the activities of informal solid waste collectors like the scavengers should not be allowed in Maitama District of the FCT. This might be connected with the unsecured nature of this sector given that most use it as an opportunity to break into houses.

\subsection{Solid waste managers' perception}

Interview conducted with the solid waste managers from the Abuja Environmental Protection Agency (AEPA) revealed that waste bins/cans were positioned at the front of residents building with which they are expected to empty their waste. The waste managers always move around to collect these wastes with their trucks 2-3 times weekly and dispose to the nearest dump site. Among the problems identified by the managers was the nonpayment of service charges by the residents of which the meagre charges do not cover the cost of waste collection, transportation and disposal. The activities of scavengers and waste pickers were also identified by the waste managers as a welcome development in the management of solid waste in the study area.

\section{CONCLUSION}

This study shows that AEPA has a structure for domestic solid waste collection and disposal in Maitama district. This structure was found to be satisfactory in the management of solid waste. Although, non-payment of waste levies by households tends to reduce the motivation of collection by the waste managers. It is therefore recommended that the AEPB should device other means to ensure that residents comply with payment for their waste since this is a major challenge that affect them. Also, proper supervision on the part of contractors should be in place to guarantee a better waste management of the area.

\section{REFERENCES}

[1] Ezema, T.O., The problems of managing solid waste in a depressed economy. Journal of Sustainable Development, 5(2), pp. 45-55, 2009.

[2] Peter, S., Karl, W. \& Jurg, C., Conceptual framework for municipal solid waste management in low-income countries. A Working Paper, 4(9), pp. 20-26, 1996.

[3] Solano, M.L., Iriarte, F., Ciria, P. \& Negro, M.J., Performance characteristics of three aeration systems in the composting of sheep manure and straw. Journal of Agricultural Engineering Resource, 79(3), pp. 317-329, 2001.

[4] Bari, Q.H., Hassan, K.M. \& Haque, M.E., Solid waste recycling in Rajshahi city of Bangladesh. Waste Management, 32(11), pp. 2029-2036, 2012.

[5] Tchobanoglous, G., Theisen, H. \& Vigil, S., Integrated Solid Waste Management: Engineering Principles and Management Issues, McGraw-Hill Book Co: Singapore, 1993.

[6] Aliyu, B.N., An analysis of municipal solid waste in Kano Metropolis, Nigeria. Journal of Human Ecology, 31(2), pp. 111-119, 2010.

DOI: 10.1080/09709274.2010.11906301.

[7] Tadesse, K., Dry Waste Management in Addis Ababa City, Ethiopea: Development Research Institute. Submitted to Ecological and Environmental Economics Program. 5-16, Addis Ababa, Ethiopia, 2004

[8] Amber, I., Kulla, D.M. \& Gukop, N., Generation, characteristics and energy potential of solid municipal waste in Nigeria. Journal of Energy in Southern Africa, 23(3), pp. 47-51, 2012. 
[9] Patrick, J., Waste Management Challenge in Nigeria. Online. www.ippanigeria.org/ privateparticipation.

[10] Ogu, V.I., Private sector participation and municipal waste management in Benin city. Environment and Urbanization, 12(2), pp. 113-117, 2000.

[11] Kgosiesele, E. \& Zhaohui, L., An evaluation of waste management in Botswana: Achievements and challenges. New York Science Journal, 3(8), pp. 37-42, 2010.

[12] Kothari, R., Tyagi, V.V. \& Pathak, A., Waste-to-energy: A way from renewable energy sources to sustainable development. Renewable and Sustainable Energy Reviews, 14, pp. 3164-3170, 2010.

[13] Fakere, A.A., Fadairo, G.F. \& Oriye, O., Domestic waste management and urban residential environment: Focus on Akure, Nigeria, International Journal of Engineering and Technology, 2(5), pp. 878-887, 2012.

[14] Zerbock, O., Urban solid waste management: Waste reduction in developing nations. school of forest resource \& environmental science. Masters international program series, No. 3, Mar. 2003. Michigan Technological University, pp. 11-43, 2003.

[15] Kuniyal, J.C., Jain, A.P. \& Shannigrahi, A.S., Public involvement in solid waste management in Himalayan trails in and around the valley of flowers, India. Mountain Forum, 24(3-4), pp. 299-322, 1998.

[16] Srinivas, H., www.gdrc.org/uem/waste/key-facts.htm.

[17] Babayemi, J.O. \& Dauda, K.T., Evaluation of solid waste generation, categories disposal options in developing countries: A case study of Nigeria. Journal of Applied Science and Environmental Management, 13(3), pp. 83-88, 2009.

[18] Troschinetz, A., Twelve Factors Influencing Sustainable Recycling of Municipal Solid Waste in Developing Countries, Houghton, 2005.

[19] Agunwamba, J.C., Solid waste management in Nigeria: Problem and issues. Journal of Environmental Management, 22(6), pp. 849-856, 1998. DOI: $10.1007 / \mathrm{s} 002679900152$.

[20] Gaza, L.Z., Effect of urban residential housing demand on land and livelihood activities in the rural areas of the federal capital territory, Abuja. Unpublished $\mathrm{PhD}$ dissertation submitted to Department of Geography, Ahmadu Bello University, Zaria, p. 6, 2008.

[21] Adeoye, P.A., Adebayo, S.E. \& Musa, J.J., Agricultural post-harvest waste generation and management for selected crops in Minna, Niger State, North Central Nigeria. Journal of Applied Sciences and Environmental Sanitation, 6(1), pp. 427435, 2011.

[22] Shafiul, A.A. \& Mansoor, A., Partnerships for solid waste management in developing countries: Linking theories to realities in the Institute of Development Engineering, Water and Development Centre (WEDC), Loughborough University, UK, 2003.

[23] Sunday, I.E., Waste disposal problems and management in Ughelli, Nigeria. Journal of Environmental Protection, 4, pp. 4-11, 2013.

[24] Wali, K.I., Investigation into the public perception towards the solid waste management system adopted in Erbil City, Zanco. Journal of Pure and Applied Science, 26(1), pp. 36-49, 2014.

[25] United Nations Environment Programme, Desk Study on the Environment in the Occupied Palestinian Territories, Switzerland, 2003. 